\title{
Identifying and Ranking Areas of Relative Need for New Public Dental Clinics Using a State-of-the-Art Data Simulation Approach
}

\author{
Y Dudko, D Robey, E Kruger and M Tennant
}

\begin{abstract}
Background: Lower socioeconomic groups and country residents are more likely to experience dental disease. Previous research has found that it is generally more cost effective to provide subsidised dental care through publically employed dentists when compared to subcontracting the work out to the private sector.
\end{abstract}

Objective: The primary objective of this study was to identify and rank areas of relative need for new public dental care facilities across Australia. The secondary objective was to gauge how many of these areas are located in the vicinity of an existing public hospital (medical) with a view to utilise existing infrastructure for future service rollout.

Methods: Usual resident population, employment status and socioeconomic distribution data was downloaded from the Australian Bureau of Statistics website at Statistical Area 1 level. A mathematical weighing formula was applied to those variables, which subsequently allowed for ranking of the results based on magnitude of the product values.
The findings were considered in terms of proximity to existing public health infrastructure.

Results: A total of 49 SA1 areas were identified and preselected as potential sites for new public dental clinics across Australia. Eighty per cent of the identified areas of relative need were located outside metropolitan areas. Fifty per cent of those were found to be in close proximity to an existing public hospital (medical).

Conclusion: Offering subsidised dental care through existing public hospitals may be an option. Such an approach has a potential to improve access to subsidised dental care in regional centres while minimising capital expenditure on infrastructure.

Abbreviations: ABS - Australian Bureau of Statistics; ASGS - Australian Statistical Geography Standard; SEIFA - Socio-Economic Indexes for Areas.

Key words: dental public health; access to oral care; oral health policy; rural health infrastructure.

\section{Yevgeni Dudko' ${ }^{1} \mathrm{BDSC}$}

Research Scholar

\section{Dennis E Robey ${ }^{1}$ BSC}

Scholar

Estie Kruger ${ }^{1,2}$ BChD, MChD

Professor

Marc Tennant ${ }^{1}$ BDSc, PhD, FRACDS (GDP), FICD, FADI

Winthrop Professor

'International Research Collaborative - Oral Health and Equity,

${ }^{2} \mathrm{School}$ of Anatomy, Physiology and Human Biology

The University of Western Australia

Nedlands, Western Australia, Australia.

\section{Correspondence:}

estie.kruger@uwa.edu.au

\section{Introduction}

The majority of Australians have access to high quality dental care services, and generally have good oral health largely due to the availability of fluoridated water and our much improved understanding of dental disease. Although the overall incidence of dental disease has reduced significantly by the end of the twentieth century, the improvements in oral health have not been equally shared across all socioeconomic groups. [1] It has been acknowledged by Australia's National Oral Health Plan that people representing low socioeconomic groups continue to experience greater levels of dental disease by comparison to their more affluent counterparts. [2]

A report titled 'Oral health and access to dental care - rural and remote dwellers' published by the Australian Institute of Health and Welfare noted that country residents are more 
likely to display symptomatic patterns of dental attendance when compared to metropolitan residents. Country residents are also more likely to experience complete tooth loss, and to not have seen a dentist in a couple of years for routine dental care. In short, statistically, country residents experience higher rates of dental disease and are less likely to receive preventive care. [3]

The demand for subsidised dental care across the country has remained consistently high over the years and often exceeds the capacity of State public dental services to provide treatment, resulting in waiting lists, with historical wait times of two years reported. [4]

Prolonged waiting time for an appointment has been identified as one of the main factors resulting in patient dissatisfaction [5] and has frequently been the source of news stories in the national media. [6]

Over the years a number of State and federal initiatives were undertaken in an effort to meet the demand for subsidised dental care. Most recently the Commonwealth Government committed A\$1.3 billion over several years to State and Territory governments to support additional dental services for adults under the National Partnership Agreement.

The measure is aimed at reducing long wait times to see a public dentist by providing eligible public dental patients with an authority to seek limited treatment from a private dentist. [7]

Previous studies have found that it is generally more cost effective to provide subsidised dental care through public dental clinics when compared to contracting the work out to private sector. [7] Thus further investment in public dental health infrastructure may need to be considered in order for us to continue cost effectively meet the demand of our growing eligible population.

The objective of this study was to identify and rank areas of relative need for new public dental clinics, and to gauge what percentage of the areas identified were located in the vicinity of an existing public hospital network (with a view to strategically place dental chairs in some of the existing public hospitals rather than build new dedicated public dental clinics).

\section{Methods}

Only open access, non-identifying data was used in this research. Thus ethics approval was not required.

\section{Australian Statistical Geography Standard}

Australian Statistical Geography Standard (ASGS) was used throughout this study. This nationally agreed approach to geographic analysis of population divides the country into four levels of clustering based around size. These are described as SA 1 to SA4. SA 1 being the smallest with about 400 people per area, SA2 closely reflects suburbs with about 10,000 people per area, SA 3 areas have about 80,000 people each while SA4 are statebased. [8]

\section{Socio-Economic Indexes for Areas data}

The data outlining the socioeconomic index for areas (SEIFA) distribution across Australia was obtained from the Australian Bureau of Statistics (ABS) website at SA1 level. [9] SEIFA has been designed by the ABS to arrange SA1s across Australia by their relative socioeconomic advantage and disadvantage. [9] The SEIFA data at SA1 level is used to calculate the SEIFA index at SA2, SA3 and SA4 levels.

\section{Resident population data}

The population data spanning all of Australia was collected from the ABS website at SA1 level. There are approximately 55,000 SA1s in Australia, together covering the whole country without gaps or overlays. [8] SA1s are commonly acknowledged to be the fundamental building blocks of the ASGS. When used in aggregate, SA1s contribute to statistics at SA2, SA3 and SA4 levels.

\section{Eligible population data}

Distribution data for the 'unemployed' and 'not in the labour force' was obtained from the ABS website at SA1 level and subsequently used to represent the distribution of the population eligible for subsidised dental care. Previous research identified a close correlation between the distribution of the 'unemployed' and 'not in the labour force' Census 2011 data and the actual distribution of the population eligible for subsidised dental care across Australia. [10]

\section{Public Hospital location data}

Geographic location data for existing public hospital network was obtained from the www.myhospitals.gov.au website. Only publically owned hospitals with emergency departments were selected.

\section{Public dental clinic location data}

Previously published research provided the physical address (and geographic coordinates) for each public dental clinic in Australia (collated from a number of open sources) as at August 2012. [11]

\section{Geographic analysis}

Quantum Geographic Information System (version 2.8.1) software was used to map statistical data and quasi-index of relative need. 


\section{Processing of SEIFA, resident population and eligible population data}

A previously developed mathematical approach to determination of areas of healthcare need, based on various smoothing functions of population disparities, was applied to the baseline data in this study. [12] In summary the method takes the SEIFA index for each SA 1 and divides it by the usual resident and eligible population data to produce a weighted number. The process is repeated at SA2, SA3 and SA4 levels. The SA1 results were added to the SA2, SA3 and SA4 area results to which each SA1 in question belonged. Thus an aggregate value for each $\mathrm{SA} 1$ is produced. This fundamental mathematical approach provides a smoothing of the 'wrinkles' in the SEIFA index between nearby SA1s and thus brings to the foreground areas that are substantive in size and population. These smoothed aggregate values for each SA1 level were arranged in an ascending order, forming a quasi-index of relative need. The most 'in need' $10 \%$ per cent of the aggregate values (ie SA $1 \mathrm{~s}$ ) were selected for further analysis in this study.

\section{Geographic disqualification}

Geographic filtering was applied disqualifying SA1s that were located in the vicinity (within $10 \mathrm{~km}$ radius for metropolitan and $20 \mathrm{~km}$ radius for country areas) of an existing public dental clinic.

\section{Results}

A total of 49 SA 1 areas ( $0.1 \%$ of all SA $1 \mathrm{~s})$ have been identified and preselected as potential public dental clinic sites across Australia. The preselection data was uploaded into QGIS software and formed a part of a layered map (Fig 1). The map allows for visual assessment of the spatial relationship between preselected sites, existing public dental clinics and the public hospital network.

\section{Figure 1: Preselection data uploaded into QGIS software forming a layered map}

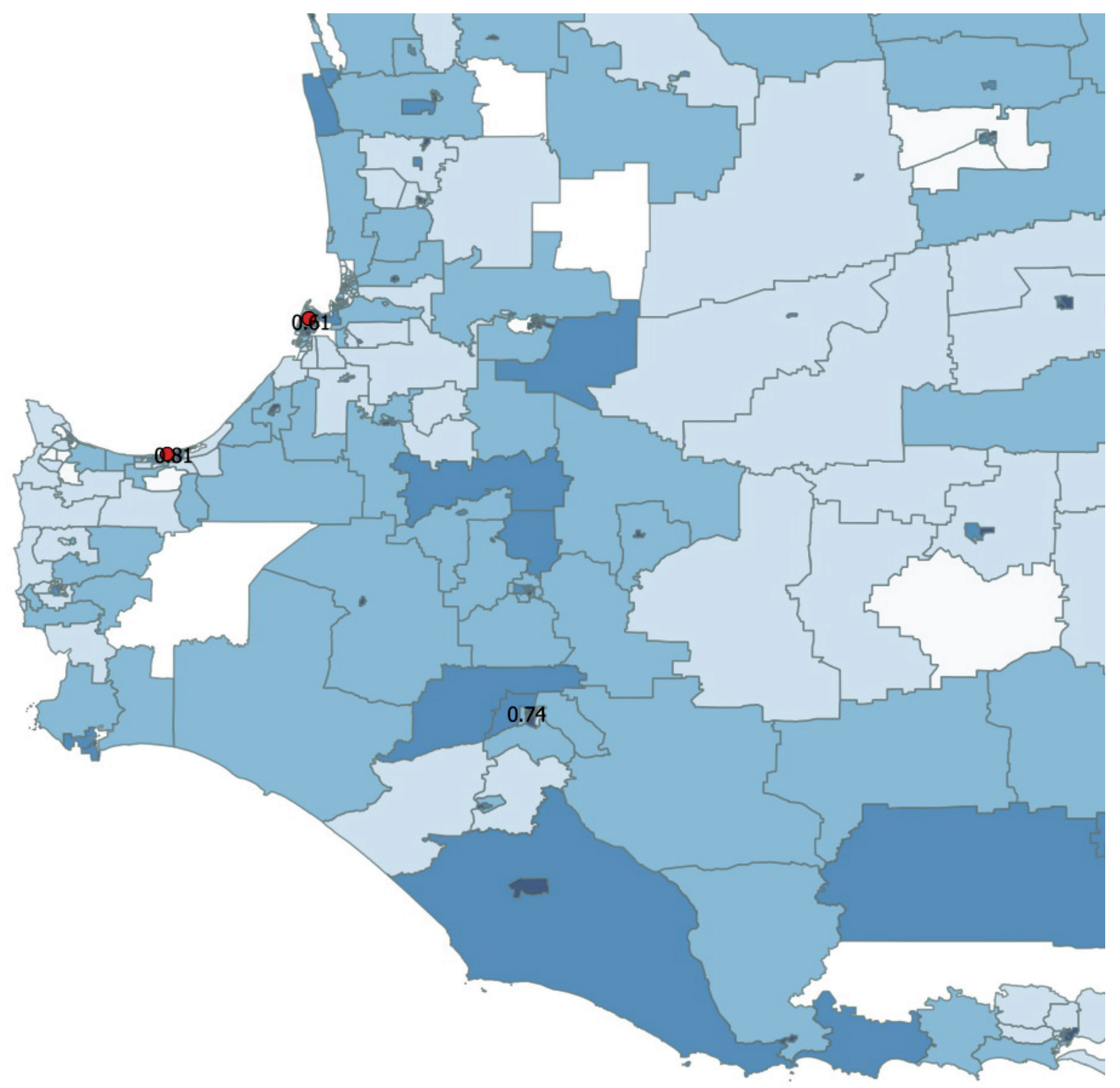


The numeric values for the identified SA1s are projecting over the map and range from 0 to 1 . Lower numbers identify areas of comparatively greater need, thus allowing us to rank and prioritise these areas for future service rollout.

An extract from the map of Australia (South West of WA) is an example of identified and ranked areas of relative need (Fig 1). Various shading indicates fluctuations in socioeconomic status of the population. Deeper shades indicate areas of low socioeconomic status, while lighter shades correspond to areas of higher socioeconomic status. While similarly shaded areas can be seen, only few display numeric values. Only areas with displayed values meet the weighting criteria of relatively higher population and eligibility levels.

Tables 1 and 2 (country and metropolitan areas, respectively) list identified areas or relative need for a public dental clinic. The majority (80\%) of the identified areas of relative need are located outside metropolitan areas. Over a quarter (27\%) of all the identified areas were located in Victoria. Queensland accounted for $24 \%$ of all the areas of relative need across the country. Tasmania was found to have more areas of relative need (14\%) than New South Wales (12\%). Northern Territory and Western Australia contributed $8 \%$ each to the total count of identified locations. South Australia made up $6 \%$ of the total, while no areas of relative need were identified in the Australian Capital Territory.

Significantly, fifty per cent of the identified areas of relative need outside metropolitan areas are located in the vicinity of an existing public hospital.

\section{Discussion}

Routine dental check-ups offer an opportunity for early detection and prevention of dental disease. For many of us the timeless proverb proclaiming that 'prevention is better than cure' rings especially true in personal health matters.

Table 1. Country locations: Identified areas of relative need for public dental clinic

\begin{tabular}{|c|c|c|c|c|c|c|c|}
\hline STATE & SUBURB & $\begin{array}{l}\text { NEAREST } \\
\text { PUBLIC } \\
\text { DENTAL } \\
\text { CLINIC } \\
\text { VICINITY }\end{array}$ & $\begin{array}{l}\text { PUBLIC } \\
\text { HOSPITAL } \\
\text { IN THE } \\
\text { IMMEDIATE }\end{array}$ & STATE & SUBURB & $\begin{array}{l}\text { NEAREST } \\
\text { PUBLIC } \\
\text { DENTAL } \\
\text { CLINIC } \\
\text { VICINITY }\end{array}$ & $\begin{array}{l}\text { PUBLIC } \\
\text { HOSPITAL } \\
\text { IN THE } \\
\text { IMMEDIATE }\end{array}$ \\
\hline NSW & Sussex Inlet & $32 \mathrm{~km}$ & No & TAS & Smithton & $92 \mathrm{~km}$ & Yes \\
\hline NSW & Katoomba & $26 \mathrm{~km}$ & Yes & TAS & George Town & $52 \mathrm{~km}$ & Yes \\
\hline NSW & Mudgee West & $35 \mathrm{~km}$ & Yes & TAS & $\begin{array}{l}\text { Central } \\
\text { Highlands }\end{array}$ & $62 \mathrm{~km}$ & No \\
\hline NSW & Tuncurry & $6 \mathrm{~km}$ & No & TAS & Geeveston & $55 \mathrm{~km}$ & No \\
\hline NSW & $\begin{array}{l}\text { Nambucca } \\
\text { Heads }\end{array}$ & $46 \mathrm{~km}$ & Yes & TAS & Forestier & $56 \mathrm{~km}$ & No \\
\hline NSW & Evans Head & $32 \mathrm{~km}$ & No & VIC & Camperdown & $50 \mathrm{~km}$ & Yes \\
\hline NT & Tanami & $430 \mathrm{~km}$ & No & VIC & $\begin{array}{l}\text { Golden Plains } \\
\text { South }\end{array}$ & $30 \mathrm{~km}$ & No \\
\hline NT & Barkly & $576 \mathrm{~km}$ & No & $\mathrm{VIC}$ & Pakenham North & $17 \mathrm{~km}$ & No \\
\hline NT & Thamarrurr & $256 \mathrm{~km}$ & No & $\mathrm{VIC}$ & Warragul & $34 \mathrm{~km}$ & Yes \\
\hline QLD & Southern Downs & $21 \mathrm{~km}$ & No & VIC & Leongatha & $42 \mathrm{~km}$ & Yes \\
\hline QLD & Crows Nest & $35 \mathrm{~km}$ & No & $\mathrm{VIC}$ & $\begin{array}{l}\text { Upper Yarra } \\
\text { Valley }\end{array}$ & $70 \mathrm{~km}$ & No \\
\hline QLD & Kilcoy & $36 \mathrm{~km}$ & Yes & VIC & Yarram & $40 \mathrm{~km}$ & Yes \\
\hline QLD & Tara & $43 \mathrm{~km}$ & Yes & VIC & Creswick & $26 \mathrm{~km}$ & No \\
\hline QLD & South Mackay & $96 \mathrm{~km}$ & Yes & VIC & Loddon & $55 \mathrm{~km}$ & Yes \\
\hline QLD & Palm Island & $51 \mathrm{~km}$ & Yes & VIC & Heathcote & $51 \mathrm{~km}$ & Yes \\
\hline QLD & Herberton & $40 \mathrm{~km}$ & No & VIC & Rochester & $26 \mathrm{~km}$ & Yes \\
\hline QLD & Aurukun & $280 \mathrm{~km}$ & No & VIC & Cobram & $34 \mathrm{~km}$ & Yes \\
\hline QLD & Carpentaria & $450 \mathrm{~km}$ & No & WA & Mandurah & $26 \mathrm{~km}$ & Yes \\
\hline SA & Ceduna & $378 \mathrm{~km}$ & Yes & WA & Manjimup & $112 \mathrm{~km}$ & Yes \\
\hline SA & Goyder & $35 \mathrm{~km}$ & Yes & WA & Halls Creek & $146 \mathrm{~km}$ & No \\
\hline
\end{tabular}


Table 2: Metro locations: Identified areas of relative need for a public dental clinic

\begin{tabular}{|l|l|l|l|l|l|l|l|}
\hline STATE & SUBURB & $\begin{array}{l}\text { NEAREST } \\
\text { PUBLIC } \\
\text { DENTAL } \\
\text { CLINIC } \\
\text { VICINITY }\end{array}$ & $\begin{array}{l}\text { PUBLIC } \\
\text { HOSPITAL } \\
\text { IN THE } \\
\text { IMMEDIATE }\end{array}$ & STATE & SUBURB & $\begin{array}{l}\text { NEAREST } \\
\text { PUBLIC } \\
\text { DENTAL } \\
\text { CLINIC } \\
\text { VICINITY }\end{array}$ & $\begin{array}{l}\text { PUBLIC } \\
\text { HOSPITAL } \\
\text { IN THE } \\
\text { IMMEDIATE }\end{array}$ \\
\hline $\begin{array}{l}\text { NT } \\
\text { QLD }\end{array}$ & Weddell & $38 \mathrm{~km}$ & No & TAS & Dodges Ferry & $41 \mathrm{~km}$ & No \\
QLD & Jimboomba & $25 \mathrm{~km}$ & No & TAS & Bridgewater & $14 \mathrm{~km}$ & No \\
QLD & Redland Islands & $20 \mathrm{~km}$ & No & VIC \\
SA & Beachmere & $17 \mathrm{~km}$ & No & WA & Folton & $18 \mathrm{~km}$ & Fes \\
Hackham West & $14 \mathrm{~km}$ & Yes & & & $13 \mathrm{~km}$ & No \\
\hline
\end{tabular}

In the context of subsidised dental care (from a tax payer perspective), prevention can also be cheaper than cure. Provision of subsidised dental care through public dental clinics has been found to be up to three times more cost effective when compared to contracting the work out to private sector. [13]

Eighty per cent of the identified areas of relative need are located outside metropolitan areas. The results were consistent with previous research findings indicating that metropolitan residents generally enjoy better access to public dental care facilities. [3]

Building a public dental clinic in a country setting may not be as cost effective as building a similar clinic in a metropolitan area, in part, due to differences in population densities. However, findings also indicate that around fifty per cent of the identified areas of relative need are located in the vicinity of a public hospital. Delivery of subsidised dental care through the existing public health infrastructure, where available, may offer an opportunity to improve access to dental care for those layers of our society that need it most, while minimising capital expenditure and the costs associated with more complex, late stage intervention.

Individual consideration may need to be given to each such case as existing public hospitals may lack the space required for a dental clinic. Co-location of dental facilities within public hospitals may be easier to enact as a part of new capital developments that meet the selection criteria. Although the cost of outfitting a dental clinic is likely to remain relatively static, shared site, development, utilities and building costs may result in significant savings when compared to building an independent public dental clinic. The co-location strategy may also help to improve patient outcomes (both medical and dental) by emphasising the link between dental health and the overall health of an individual and promoting preventive behaviour. Closer integration of medical and dental services can offer a more coordinated, efficient, patients-centred approach that meets both the medical and oral health needs of patients in a single setting. [14]

Poor oral health has been linked to chronic conditions such as heart disease and diabetes. [14] Co-location of medical and dental services has been found to simplify access to dental care and improve health outcomes by allowing for timely delivery of diagnostic and therapeutic care. [14] There are a number of examples where co-location of hospital and public dental clinics has been successfully implemented eg, Geraldton Hospital, Western Australia and Tully Hospital, Queensland.The demand for subsidised dental care remains consistently high, often exceeding the capacity of the public system to provide the service, resulting in long waiting lists. [4] Thus a strong argument could be made that our policy should be to widen and strengthen the government provided dental network to build the superstructure of a great compassionate system to leave no Australian behind. This research is based on quantitative data from the ABS.

Thus, application of the method produces consistent, precise and reliable results. The identification and ranking process described, however, may not address qualitative issues unique to each site. Additional qualitative considerations should be given to each proposed location as these will often complement and allow for refinement of the quantitative data.

\section{Conclusion}

The areas of relative need identified in this study represent the most disadvantaged $(0.1 \%)$ of the Australian population. Country residents are more likely to experience dental disease when compared to metropolitan counterparts. Regular dental check-ups can aid prevention and early identification of dental disease. Access to subsidised dental care can potentially be improved in half $(50 \%)$ of the 
identified areas by offering subsidised dental care to the eligible population through the existing publicly owned hospital network.

Offering subsidised dental care through the existing public hospital network, where available, in turn, may help to control the cost of service delivery by minimising capital expenditure.

\section{Acknowledgements}

None declared.

\section{Financial support}

Nil.

\section{Competing Interests}

The authors declare that they have no competing interests.

\section{References}

1. Australian Institute of Health and Welfare. Health inequalities in Australia: morbidity, health behaviours, risk factors and health service use [cited 2015 Oct 17]. Canberra: AlHW; 2006. Available from: http://www.aihw.gov.au/WorkArea/DownloadAsset. aspx?id $=6442459734$

2. Australian Dental Association. Socioeconomic status and oral health [cited 2015 Oct 18]. St Leonards: ADA; 2006. Available from: http://www.ada.org.au/app_cmslib/media/lib/0702/ m44818_v1_socioeconomic\%20status\%20and\%20oral\%20 healthsep_06.pdf

3. Australian Institute of Health and Welfare. Dental Statistics and Research Unit. Oral health and access to dental care - rural and remote dwellers [cited 2016 March 10]. Canberra: AlHW; 2005. Available from: http://www.aihw.gov.au/publicationdetail/? id $=6442467750$

4. Australian Government. Dental Health Services. Annual report 2014 [cited 2015 Nov 18]. Perth: Dental Health Services of Western Australia; 2014 . Available from: http://www.dental.wa.gov.au/ about/DHS\%20Annual\%20Report\%20June\%202014.pdf

5. Chu CH, Lo ECM. Patients' satisfaction with dental services provided by a university in Hong Kong. Int Dent J. 1999;49:53-9 doi:10.1111/j. 1875-595X.1999.tb00508.x.

6. Australian Broadcasting Corporation. Public dental waiting list blowout prompts call for subsidised scheme in WA [cited 2016 Jan 18]. Perth: ABC; 2015. Available from: http://www.abc.net.au/ news/2015-11-13/dental-waitlist-blowout-promptscall-forsubsidised-scheme/6937778

7. Dudko Y, Kruger E, Tennant M. National dental waitlists: what would it take to reset to zero? Aust Health Rev. 2015;40(3):277-281. Available from: $\mathrm{http}: / / d x$. doi.org/10.1071/AH15025

8. Australian Bureau of Statistics. Australian Statistical Geography Standard [cited 2016 Feb 13]. Canberra: ABS; 2016. Available from: http://www.abs.gov.au/ausstats/abs@.nsf/Lookup/2901.0 Chapter23102011

9. Australian Bureau of Statistics. Socio-Economic Indexes for Areas [cited 2016 Feb13]. Canberra: ABS; 2016. Available from: http:// www.abs.gov.au/websitedbs/censushome.nsf/home/seifa

10. Dudko Y, Kruger E, Tennant M. Geographic distribution of point-intime access to subsidised dental services in Western Australia. Aust J Prim Health. 2016;22(6):569-579.
11. Tennant $\mathrm{M}$, Kruger E. A national audit of Australian dental practice distribution: do all Australians get a fair deal? Int Dent J. 2013; 63:177-82. doi:10.1111/idj.12027

12. Dudko Y, Kruger E, Tennant M. Selecting a location for a community health infrastructure: Combining a mathematical approach with Geographic Information System to rank areas of relative need. (Submitted to Asia Pacific Journal of Health Management.) 2016-0015

13. Dudko Y, Kruger E, Tennant M. Is mix of care influenced by the provider environment? A comparison of four care pathways in oral health. Aust Health Rev. 2014;39(1):51-55. http://dx.doi.org/ 10.1071/AH14064

14. Pourat N, Martinez AE, Crall JJ. Better Together: Co-Location of Dental and Primary Care Provides Opportunities to Improve Oral Health. Los Angeles, CA: UCLA Center for Health Policy Research; 2015. 